Accepted version of Lee, A. and Boud, D. (2003). Writing groups, change and academic identity: research development as local practice. Studies in Higher Education, 28, 2, 187-200.

DOI: $10.1080 / 0307507032000058109$

\title{
Writing Groups, Change and Academic Identity: research development as local practice
}

Alison Lee and David Boud, University of Technology, Sydney, Australia

\begin{abstract}
The development of the research potential of university staff has been given less attention than many other aspects of professional development, particularly teaching development. Yet there is an important need for the development of staff in the research role in the light of growth of higher education and changes to the organisation of the sector in many countries. This article examines one strategy for research development: the use of writing groups. It argues that writing is best seen as a starting point, rather than an endpoint, of the research process and hence that fostering academic writing is a useful place to do research development work. The article provides details of the use of a number of writing groups over three years in a particular faculty and explores the responses of leaders and participants. It identifies factors important in the use of this strategy and focuses on the contextual conditions required for initiatives of this kind to be effectively implemented.
\end{abstract}

\section{Introduction}

As higher education has expanded and restructured in recent decades, the specialist field of academic development emerged to meet new needs. Formerly, the culture of autonomy engendered within the older universities saw development for individual academics as a matter of direct enculturation, or perhaps implicit apprenticeship, within a culture of laissez-faire collegiality. In the new environments this 'invisible college' is not adequate to the requirements of new cohorts of students, new disciplines and professional fields and new kinds of higher education workers who have had to come to understand what it means to be an academic. Explicit attention to developing the capacities and practices of academic work was needed, and a specialised field of research and practice grew to meet this need. Specialist units or centres for academic development, variously titled and conceptualised, have been set up in many, if not most, universities.

Driven by the very visible needs of expanded and diversified cohorts of students, however, the new academic development groups focused their attention predominantly on the improvement of teaching (Boud, 1999). By and large this remains the case today. Academic development for research has been often neglected except in individual universities as part of local research policy development; it has been little researched as an endeavour for the development of academic capacities and little documented.

This article argues the need for systematic attention within the field of academic 
development to be devoted to the development of capacities for, and practices of, research, together with a focus on the need for the development of new academic 'identities'. Within the former non-university sector and the new professional areas, new cultures of research and scholarship need to be forged. In both of these areas there are still substantial numbers of staff without doctorates, or with research training in disciplines different to those in which they currently practise. While there have been significant completions of doctorates, the experience of doing a research degree-often on a part-time basis with many home and work pressures - has not been sufficient to complete a research training and produce competent and confident independent researchers. Systematic attention to the further developmental needs of individuals and the departments or faculties in which they are located is, we argue, necessary to bring about successful cultural change in an increasingly normative and performative environment.

The article discusses an initiative for research development, conducted over three years, involving the formation of research writing groups for members of the academic staff in the faculty in which we work. These groups had an explicit brief to promote research and to develop the research capacities of members of academic staff through a programme of writing for publication. Discussion of this initiative illustrates two points in our argument concerning the contextual conditions for effective and sustainable academic development practices. The first, more specific, point concerns the central role of writing in the research process, and hence the need to attend explicitly to it as a site for developmental intervention; this point will be elaborated later.

The second, more general, point concerns the need to conceptualise academic development as a 'local practice', and as a practice of peer learning in the workplace (Boud, 1999). We argue that development activity in relation to research and scholarship makes little difference in the long term if it is isolated from 'normal' academic practice or from the particular setting in which people operate. Such activity needs, we suggest, to be directly linked to the development of university fields of practice and the enhancement of peer relationships within local settings. While development of relationships between and across faculty or university boundaries is desirable, approaches to research development which build local relations and which occur in sites of learning close to the context of daily work are thus preferred over those organised and conducted outside a faculty. Through focusing on such practices, this article builds and elaborates on a conception of academic development (articulated in Boud, 1995, 1999), which distinguishes itself from the overwhelming emphasis in academic development literature on centralised provision.

The principal reasoning for this position concerns the key importance of the question of identity (Bauman, 1996; Hall, 1996) in academic development work, and the significance of the emotional dimensions of identity formation. Questions of change pose both threats and opportunities to individuals, often challenging fundamental conceptions of self and self-worth. Of the recent changes in higher education, it is arguably the expectation for all academics to undertake research that has generated the greatest threat, as well as some of the greatest opportunities for change. Academic identities, including identities as researchers, are forged, rehearsed and remade in local sites of practice. Fundamental issues for any conception of sustainable academic development involving change and 
identity are, we suggest, those of fear and desire. These are not just matters of individual feeling, but rather, are structurally generated and locally inflected within the ecologies of specific work sites.

The remainder of this article situates the current needs for research development within the emerging set of conditions of academic work more broadly, then offers a rationale for the usefulness of focusing on writing as a site for intervention for research development. Through a description of the writing group initiative, we elaborate a set of principles which we believe develops and exemplifies the argument concerning the need for a contextualised, local approach to academic development. In doing so, we focus on the importance of considering how development activities interact with academic identity formation and the desires of those for whom development is intended.

\section{The Emerging Scene of Academic Work}

The research function of universities has both expanded and significantly changed its character with the growth and reorganisation of the higher education sector over the last several decades. Rather than being an élite activity undertaken by specialised groups in a small number of institutions funded specifically for the purpose, research has come to refer to the 'normal' work expected of most academic staff, as read from institutional texts such as workload formulae and promotion criteria. This shift has had profound implications for both individual staff and whole institutions, as they have struggled to redefine the nature of their work and to adopt new practices for which they have not been systematically prepared. A significant need emerged in the 1990s and into the new century for the development of research capacities for academic staff in a variety of contexts, in particular in the new universities and in new disciplines and professional fields formerly not part of the university sector.

In more recent years, pressures on academics have greatly increased, in the sense that academic work has come to embrace new and ever-more diverse forms of activity. Individual academics are facing new challenges to their work in an increasingly competitive climate. There are pressures to find new forms of funding for many core academic activities, including both teaching and research. In the case of research, these pressures have intensified in recent years, for example, in Australia with the release of the Government White Paper on research and research training (Kemp, 1999), with its emphasis on performance-based funding, research concentrations, research degree completions, preparing research students for employment, and 'accountability'. This creates an additional emphasis on finding ways of supporting the research dimension of academic work.

In this climate, in addition to the widely acknowledged intensification of work that these changes have brought, there has been an increase in self-questioning, by both individuals and institutions, concerning the nature and value of the academic enterprise and their place within it. The changing conditions of academic work have created fear and anxiety, as well as offering the possibility of new forms of satisfaction and pleasure in a richer and more complex environment. A major assumption underpinning our argument concerning productive and sustainable academic development here is that it must work with, and 
make visible, what is often left out of official accounts- the emotional dimensions of development and change. We suggest further that academic development is crucially about the making and remaking of academic identities (Lee \& Green, 1997). In the contemporary environment in higher education, it is important to acknowledge that many academics are at best ambivalent about change and are often overtly anxious and fearful. To work with and against debilitating emotions such as fear requires an explicit engagement with its obverse: with trust and the location of positive desire in individuals' work lives. Later in this article we elaborate the way in which we understand the importance of notions of desire in academic development and change. Academics, as other workers, desire to 'do a good job', to feel competent and valued, to learn in a supportive and enabling environment and to take pleasure in their work. An approach to academic development that attends to questions of identity and the emotions will thus focus on strategies to mobilise desires to engage in the kinds of activities which will achieve those goals. The relationship between fear and desire is a complex one; we therefore suggest that any plausible explanation for why some develop- mental initiatives work while others do not must take this relationship seriously into account. That is, any change strategy needs to be mindful of how fears can be managed and desires developed productively.

The contemporary challenge for academic leaders is increasingly to bring academics into productive relationships with each other, to identify and support fundamental values and activities, including research. There is a need to help academics identify new goals and desires in the changing climate and to help them locate themselves in a productive relation- ship to change. In sum, there is a need to promote and develop new forms of academic practice, in order to facilitate development in directions strategically identified. It is in this context that we understand the nature of the formation of research writing groups as a useful development initiative. The writing groups in this account became a locus for the investigation of fundamental questions of academic identity with particular reference to scholarly work and publication in one workplace. It is in relation to these issues that we seek in the final part of the article to elaborate some general principles for evaluating the writing group's effective- ness as a strategy for academic development.

\section{Research and Writing}

It could be said that, in the light of the current challenges of change in higher education, there have never been more reasons to write (Jones et al., 1998). At the same time, as relationships among core academic activities both proliferate and blur, there is an increased and diversified function for writing. This diversification extends to the writing of project tenders, grant applications, electronically mediated or print-based course materials, policy documents and the like. Despite this proliferation, and in complex relation to it, the scholarly peer-reviewed journal article has until now maintained its central position as a key indicator of academic identity and worth. Indeed, in an era of rapidly accelerating globalisation of higher education, the peer-reviewed journalwhether print-based or electronic_-becomes a key site where this identity is performed and recognised worldwide. It has to be acknowledged, of course, that the 'new' collaborative relationships between universities and the broader community may effect significant changes to this status quo (Gibbons et al., 1994, Garrick \& Rhodes, 2000, 
Symes \& McIntyre, 2000).

For our purposes of research development, we identified scholarly writing as a key site for the generation of fear and anxiety, as well as desire, in a significant number of academics in our workplace. We have elaborated elsewhere a rationale for focusing on writing for publication, reversing a common argument concerning the linearity of the research process, in which 'writing up' is the last rather than the initial activity (Lee, 1998). Briefly, the developmental argument is that, by beginning with skills and practices of writing, capacities and dispositions for research can be developed in a supportive peer environment. Writing groups serve many developmental functions. They disrupt the commonplace and, often, debilitating fantasy of writing as a solitary activity (Gere, 1987; Brodkey, 1996), and build on those aspects of academic writing that are collective and peer-based. What is explicitly acknowledged is that scholarly writing, while often carried out alone, enters into a network of peer relations: conference presentations, collegial critique of draft texts, the peer review process in journal publishing, etc. Writing groups can function to demystify the process of scholarly writing and publication, to build skills of review and critique, to provide early audiences for draft texts, and so on.

There are many accompanying personal issues for those undertaking such development, which can be summed up as concerning what is at stake in changing work practices and commitments, from a predominantly teaching culture to one which also fosters and rewards research, however defined. Crucially, writing groups offer a place where issues and dilemmas about research and writing can be 'externalised' from the individuals who experience them, and considered in terms of the institutional conditions of their production (Grant \& Knowles, 1999; Saunders et al., 1999). It is in the ensuing discussion of the functioning of writing groups that the importance of the focus on identity, fear and the moblisation of desire in academic development work can be elaborated.

\section{A Study of Writing Groups}

The writing groups which form the basis of this discussion were formed within an institution that had gained university status in 1990. The Faculty of Education where they were located is based on two campuses 18 kilometres apart. Each campus had a different history and culture. As part of strategies to foster the development of a research culture throughout the university, many initiatives had been taken. Institution-wide workshops on research development had been provided, and there had been a research mentoring programme as well as release-time given to complete doctorates. Within the faculty, research centres had been established, commissioned research grants had been successfully sought, and publication rates had substantially increased.

By 1996, however, university-wide support for research development had been reduced and a substantial increase in research funding and publication output had started to plateau. Buoyed by its earlier success, the faculty wanted to strengthen its achievements and develop further in research. A need to provide explicitly and systematically for research development was identified. Many staff had gained doctorates or were close to completion, most had made contributions to conferences, but research and scholarship 
was seen by too many as some- thing undertaken in addition to, or perhaps more accurately, as ancillary to, teaching responsibilities. As a response to this cultural challenge, research began to be included as part of workload formulae and seminars about publishing were conducted.

In this climate, the idea of forming staff groups oriented around writing for publication was seen as the next step in the formation of an appropriate academic culture within the emerging policy environment. A first writing group was initiated, focusing on the needs of 'new' researchers. These were identified as those either new to academic work or those changing the nature of their work and their role in the faculty. A year later, spurred by the aspiration to address the research development needs of a wider group of staff in the faculty, and the overwhelmingly positive views of those who had taken part in the first group, a second group was formed. This group was designed to meet the needs of those already published but who wished to extend their writing activities as part of a supportive and collective endeavour. This group was represented as being of benefit to those who had published at least one article or a chapter in a book, but who do did not view themselves as regular writers or researchers. The convenors of the groups were the authors of this article: experienced researcher-writers, one who had had been involved in group-based research- writing development activity (AL), and one with a background in writing for publication, editing and academic staff development, but with no experience of teaching writing (DB). Each worked with a separate group and operated mostly independently of the other.

The activities of both groups were documented and experiences of participants recorded. In addition to evaluative data collected as a normal part of the activity from members of each group each semester, material for the present article was drawn from detailed records of activities and responses to them kept by the group leaders, an e-mail-based survey of members of all groups, and papers prepared for conferences about the writing group process by members of the group. Subsequent analysis by the authors, comparing and contrasting experiences of the two groups and conceptualising them in terms of literature cited here, led to the present representation. This article was discussed in draft form in these writing groups and modified in the light of their comments.

\section{The 'New Researchers' Group}

The first group was initially formed with eight members, rising to 10, and had a life of two years. It met fortnightly, and then weekly, for two hours each time. The initial conception of the group was that it would involve a combination of workshops and individual consultation with a view to fostering collaborative self-support activity. It would generate concrete outcomes for each participant as appropriate for their level of skill and experience and their own goals.

Because of the history and particular characteristics of the members of this group, it was necessary to approach the task of setting goals and securing a common commitment to those goals with considerable sensitivity. It was clear that the agenda was not, in any straightforward way, just about 'writing', but as much about the positioning of the participants within a changing workplace context and its attendant pressures and 
challenges. To give a sense of how the group proceeded to clarify its goals and its tasks in its early stages, this reflection on the experience of the first few months by one participant is instructive:

Inexperienced writers often have a lack of confidence about writing, which can lead to reluctance to start .... There has been an agreement on confidentiality so that people feel they can discuss their fears and weaknesses without fear of them being repeated outside the group.

The group worked in its first few months to identify overarching themes within which it would conceptualise its agenda and organise its repertoire of tasks and activities. These themes emerged as: questions of identity-making the shift in a changing Faculty of Education from 'adult educators' or 'teacher educators' to 'academics'; 'know-how' in relation to writing for publication-encompassing such matters as using conferences strategically, analysing key journals and their practices of submission; and, of course, the practices of writing itself. The group developed a language for talking about writing, which included a focus on such things as genre, rhetoric and the grammar of academic English, as and when it was useful to explicate effective writing strategies. Writing during group sessions was used as a deliberate strategy to build confidence and generate text that could be worked on between meetings.

\section{The 'Extending Publication' Group}

Unlike the first group, which comprised staff from one campus, the second included those from both campuses, who hitherto had had little opportunity for professional interaction with each other. At first there were seven regular members, in addition to the convenor. They met initially weekly, then fortnightly, over a semester. The aim was to provide support for staff who wished to write for publication. The emphasis was on fostering collaborative self-support activity and on generating concrete outcomes for each participant as appropriate to their level of skill and experience and their own writing goals. By 2002 the group had encompassed 15 members, had met under another convenor for a semester; further, a third writing group had been established for a year. The central emphasis on providing feedback on writing continued throughout.

Participants were expected to make a commitment to participate in all meetings, to engage regularly in writing throughout the year and to bring their writing to the group. Specific activities were determined by those who took part; topics about varying aspects of writing, publishing and academic work were identified and discussed.

Although this group of staff had more experience in writing, many of the themes of the first group recurred. There was a focus on the development of peer relationships and identity as academic writers; 'know-how', though this manifested itself in different ways; and productivity as people who publish. The diversity of the group in terms of differing physical and disciplinary locations (though all within the same faculty) proved to be an important feature. At first, members of the group expressed views that indicated their doubts about their ability to contribute to those in other academic specialisations within the broad field. As the group progressed, however, the commonalities of interest in 
constructing a paper, of understanding the journal publishing process, and sharing drafts led to a realisation, shocking to some, that they really were colleagues engaged in the same business as each other, with common concerns and desires. To share what they cared about with colleagues involved in a similar project created a space of genuine academic and educational engagement absent from day-to-day meetings:

I ... found it useful to be part of a group in which all members submitted themselves to the process of reading, writing and being read. Because the context itself was a supportive and constructive one, criticism was much easier to take and talking together about a piece of writing seemed to generate a new level of shared awareness about what worked and what didn't work.

Even though many participants had completed research degrees and most had already published something in a journal, their level of knowledge about publishing was surprisingly low. They were familiar with the journals in their field, but as readers of the content published, not as writers or discriminating consumers of journals as publishing vehicles. They appreciated discussion with a journal editor to find out what went on 'behind the scenes' and to understand how to read the significance of the letters written by editors which accompany referees' reports. There was a greater emphasis on productivity during the life of the group than in the group of new researchers. All were successful in producing at least one article or book chapter ready for submission. In the first cycle, 10 articles discussed in the group were published.

\section{Considerations for Practice}

In this section, we seek to extract, from the practices of the writing groups, a set of principles for successful development which might be generalised to other local sites of practice. While significant to our understanding of the necessary conditions for successful research develop- ment, as principles they remain necessarily abstract, requiring local conditions and circum- stances to be mobilised for them to be operational, robust and sustainable. Three general points of principle have emerged from our exploration thus far. We will outline them here, sketching briefly how in the case of the two groups these points of principle were realised.

\section{Mutuality}

The first of these principles refers to what we will term 'mutuality'. Typically, relationships among academic staff are characterised as 'collegial', a notion predicated upon the traditional 'autonomy' of the academic. While hierarchies exist, in terms of managerial function, promotional position and what we might term, following Bourdieu (1986), 'symbolic capital', they do not involve direct lines of control and can be decentred in the interests of autonomy. The idea of collegiality is often invoked as a desirable goal, one to which many academics are deeply attached. Yet an excessive attachment to academic autonomy often leads, in our experience, to isolation for many. This is particularly so for those who, in seeking to position or reposition themselves within a research culture, find themselves lacking the necessary resources for building productive collegial networks. Traditional ideas of academic collegial- ity and autonomy 
mask the need for new kinds of relations to be built, which recognise the new conditions in which academics work.

Mutuality is a term we use to disrupt the effects of an excessive attachment to notions of academic autonomy. The achievement of a rich peer relationship involves recognition both of a common positionality, in some fundamental sense, and a common project. In our study, an important aspect of the common project for the writing groups has been recognition of the need for cultural change within the faculty. Meeting individuals' own developmental needs has served at the same time to build a common change project of producing a faculty research culture. The idea of mutuality or peer-reciprocation, to supplement or even displace older, laissez-faire notions of collegiality, involves explicit attention to identifying the organisation's developmental goals, the needs for change and development of its members in meeting those goals, and active working to build collective strategies to meet those needs.

The writing groups were an explicit strategy for building mutuality in relation to research and scholarship. Reciprocity was a necessary condition for the successful and sustainable functioning of the groups. In addition, however, the possibility of a substantially enriched peer relationship was one result of such groups. The essential elements of a rich, mutual, peer environment in relationship to the writing groups were, first, that all members came to speak confidently out of their own experiences of writing and reading; second, that members were comfortable addressing each other directly about the other's writing; and third, crucially, that the relationship was reciprocal. The dynamics of turn-taking centrally involved reciprocity at a number of levels, from the micro-level of interaction within group meetings to the taking-up of multiple roles within the group at different times. A significant distinguishing feature of the writing groups was that every member took a turn at every one of the roles available within the groups.

This notion of mutuality does not equate to a flattening-out of differences, however. Differences were accommodated within a larger commitment to a group project. Indeed, in some cases the differences which members initially felt would pose difficulties became distinct advantages in the enhancement of possibilities. For example, as noted earlier, a mixture of academics from different locations and disciplines, far from being a limitation, proved to be an important feature of the groups. This became even more tangible when members of the group spotted issues in the drafts they were reading which linked directly to matters they had been concerned about in their own work. Although, for example, one person was engaged in a (post-)structural critique of globalisation and another in the role of the special educator in the classroom, the challenges of writing brought them together in a context held together by deeper educational commitments than the writing site or the forms of conceptualisation used. To share what they cared about with colleagues 'doing the same’ created a space of academic and educational engagement.

Differences in experience and expertise between group members and convenors were also exploited productively in many instances. One of the groups required, and demonstrably enjoyed, direct teaching by a person with expertise in writing (Saunders et al., 1999). The acquisition of a vocabulary for talking about and intervening in the process of writing was a significant feature of this group's activities, especially in the 
first months of its operation. A pivotal point in the development of another group occurred during the third meeting, when the convenor was asked if he would be bringing his own writing to the group. His agreement to do this and the subsequent enacting of this decision seemed to cement a commitment to mutuality and peer-reciprocation in the group and showed that it was for the benefit for everyone, not just the least experienced. What is important in these two examples is that, in identifying and working on common goals, hierarchic power relationships are backgrounded, and a collective purpose involving reciprocal action is foregrounded.

It is also not the case that notions of autonomy need to be simply refused. While a respectful peer environment is necessary for new and less experienced writers to submit their own unfinished work to group review, the specificity of the writer's own purposes and goals in writing must also be respected. Indeed, there is a delicate balance to be achieved between a productive taking-up of the agendas of particular members' projects by the group and an inappropriate appropriation of those agendas. At different points in the writing process, the group interactions might influence the shaping of a writing project, help to surface possibilities and directions, or take on a more editorial, readerly function. At all times, the groups' task was to assist a writer to position themself within their own writing, within the text and within the particular community of readers to whom the text was addressed.

The commitment to collective ways of working on writing, then, entails a respect for differences at a number of levels. What is clear, though, is that such a commitment is in many respects counter-cultural within universities. Despite the fact that writing groups have a long history within academic institutions (Gere, 1987), writing has been conceived and practised largely as a solitary activity. Further, in many disciplines, work practices in general are solitary and private-teaching, for example, largely still goes on behind closed doors. Promoting a group approach to writing development works actively to break down such sedimented practices, creating unprecedented spaces for dialogue across positional differences.

\section{Normal Business}

The second principle is that successful research development must become 'normal business' within the daily life of the workplace. This involves building the activities into the ways in which the organisation governs itself, organises itself and plans for its future. It involves building upon existing advantages, opportunities and priorities, using available expertise, and linking, wherever possible, with other priorities of the organisation. In terms of what is learned and practised in group activities, the focus is on 'know-how': practical, procedural measures for playing the particular writing and publishing game of the discipline and for building these practices into the goals of the local faculty or department. In an immediate but significant sense, notions of 'normal business' also require group meetings to fit the timetables and work plans of participants.

The acquisition of 'know-how' was a key feature of how research writing came to become 'normal business' in the work lives of many group members. In this way, practical know-how merged with the development of local practices, including setting 
deadlines, peer critique of drafts and building collaborations and joint publication. Examples of discussions regarding know-how that were valued highly by group members included using conferences strategically, identification and analysis of key journals and the practices of submission, positioning in relation to 'rejection' letters and the sharing of time management strategies.

The development and support of practical writing and publishing goals was a further key feature of the 'normal business' focus. In different ways and at different rates, all group members committed themselves to producing at least one article or book chapter ready for submission during the life of the group. Many articles discussed in the groups were made ready for publication and, at the time of writing, a large proportion had been published. To evaluate the practical effectiveness of the groups, a number of 'measures of success' were generated by the groups. These included the experience of practical support in members' own writing, and encouragement to produce-including the setting of deadlines and peer expectations. Other measures were identified as the enhancement of intellectual quality, the learning of techniques for improving efficiency, and the importance of affirming the importance of research-writing in members' lives.

The achievement of 'normal business' was not just a feature of the activities and relationships developed internally in the groups, however. There was an important develop- mental policy aspect. In this particular faculty, the 'normality' of the writing groups was achieved through a variety of policy measures. The need for a focus on research development had been included as an objective in the faculty's Research Management Plan. Writing groups were explicitly written in as strategies for meeting the objective, with targets involving productivity-based outputs. Funding was attached to the writing groups, first in terms of a workload allocation for the convenors, then for the other participants. From the convenors' point of view, it was important to signal that this was regular 'work', neither an ancillary extra to normal workload nor a charitable donation of labour and expertise. For the other participants, time was allocated as part of a refinement to an existing practice of allocating ' $\mathrm{R} \& \mathrm{D}$ ' time upon application. A workload formula was developed and refined in which research and writing was factored in as 'work', alongside teaching and supervision. A portion of the notional research budget was allocated to the 'development' side of R \& D. An individual could obtain 'D' workload time through participation in a writing group for a given period. This was funded out of income partly earned through research productivity dividends and a reassignation of priorities. The principle of normal business was thus formally inscribed through strategic planning and budgeting. Once the groups had developed their own justification and momentum, funding was reduced and then eliminated.

There is, however, a tension between the principle of normal business and the imperative to create space outside particular kinds of work patterns which militate against the development of productive research practices and rich peer relations around research development. The writing groups clearly acted as enabling micro-environments in what was perceived of as an otherwise often unfriendly mainstream working environment. In this way, writing groups functioned as privileged spaces (Boud \& Miller, 1996). They provided continuity in fragmented work lives and they built relationships across restructured institutional boundaries - particularly across the two campuses of its 
operation-which would not otherwise have been fostered. In this sense they were experienced as extraordinary and valued as such. The very nature of 'ordinary work' is that there is little space for new activities and new ways of being with each other. It is only through the creation of the extraordinary that cultural patterns can be disrupted and new forms of 'ordinary work' made possible.

\section{Identity and Desire}

The third principle was identified earlier as a key element in academic development work. We suggested that attention to questions of desire, identity and the emotions are crucial to the sustainability of any developmental activity, yet they are often ignored. Here we focus on the notion of desire as a potentially positive force in work life- that which will drive an academic to build and sustain activity. Desire has been theorised within the disciplines of philosophy, psychoanalysis and cultural studies (see Fuery [1995] for a useful overview). For our purposes, we draw most on contemporary philosophical discussions of desire and their take-up within educational theorising (e.g. McWilliam, 1995; McWilliam \& Taylor, 1996; Boler, 1999). Desire in this work involves both a force - that which impels people to act - and form - the particular shape that desires come to take in response to changes in the external environment (Deleuze \& Guattari, 1983). Desire in this sense is positive. It can be understood as a 'primary active force' (Patton, 2000, p. 70). It is productive in the sense that it 'produces real connections, investments and intensive stages within and between bodies' (p. 70). For our purposes, desire produces change; individuals invest in that change and the new forms of identity made possible. In doing so, they enhance their capabilities in new desired directions. What is necessary for any productive enhancement of skills and capacities, we argue, is the desire to use them to engage in a community of practice that recognises and rewards the user. Theorising desire in academic development is, we contend, a most important need for the field.

In reviewing the writing groups, and the dynamic and sustained nature of their operation over several years, it is clear that fears were surfaced and desires were mobilised, harnessed and resourced. A desire on the part of the participants to become researcherwriters clearly warred in many with the fear and anxiety accompanying often inflated notions of 'research', and their own inexperience. For example, in one of the groups which involved members who self-identified as new researchers, members brought many implicit assumptions about the nature of research, the nature of writing and their relationship to these activities to the first meetings. Notes from these meetings, and the reflective and evaluative writing undertaken regularly by participants, identified assumptions about writing that had remained largely unconscious until interrogated through the group process. The securing of confidentiality was essential in creating the space where these could be surfaced and spoken, their irrationality acknowledged and worked through, and positive desire articulated.

The question of identity in relation to academic work was a major issue for many participants in this group (see Bauman [1996] and Hall [1996] for useful overviews of contemporary theories and debates about identity, and Mansfield [2000] for a recent discussion of the related concept of subjectivity). Academic writing was a touchstone for 
the surfacing of many major questions concerning identity and change. Issues of fear and desire worked together to impact often dramatically on images of personal competence. Loss of old identities and sets of 'core' values as particular kinds of worker-educators needed to be acknowledged and worked through. Issues of pleasure and 'identification' with the new positions available within the new higher education policy environment had to be articulated. Over the life of the groups, questions of identity began to overlap with notions of 'know-how', as group members came to take up certain kinds of position which enabled them to want to and be able to write and publish.

Desire is also clearly a factor on the part of us, the convenors of these groups. We experienced the desire to contribute to the 'becoming' (Patton, 2000) of researcherwriters. This desire was experienced on the part of the three convenors of the groups, as well as the group members, and was needed to sustain impetus, alongside the tensions and vicissitudes of current academic work. These desires were part of the unstated, but powerful motives that fuelled the development initiative. As convenors we had a longstanding investment in and commitment to both professional development and scholarly writing and publishing. In the context of this development, there was a particular commitment to the demystification of research and academic publication. The theme of 'know-how' is geared to this demystification process, one which is clearly crucial to the attainment of sustainable rich peer relationships. We 'cared' about the need for resourcing such know-how.

To the other group members, the transmission of specific 'secret' knowledge about writing and publishing was of a lower priority relative to the demystification and opening up of knowledge required for writing and getting published. Once 'secrets' were revealed, for example, in the decoding of acceptance/rejection letters from editors, then group members could use their own resources to gain the specific knowledge they needed to get their own writing published. The pleasure involved in understanding the code or appreciating for the first time what experienced colleagues 'knew' as an apparent matter of course is impossible to overestimate. For staff who did not see themselves as full members of the 'club' in which they seemed to be inadvertent participants, to discover that they were closer than they realised, and that their investment was not in vain, was a potential source of pleasure. To add to this, their new-found ability to assist each other without loss to self, indeed, rather the opposite-an enhancement of their own capacities - compounded the value of their participation.

Accompanying these investments are the satisfactions and pleasures in experiencing the fulfillment of goals, the production of tangible outcomes, the repositioning of selves. Pleasure also has to be substantially located within the processes of 'doing' the writing groups. The fact that the writing groups have been deeply satisfying to all participants is clearly a major factor in their success. Within the lived experience of the writing groups, the pleasure articulated by members might be understood in terms of a cycle of constant re-articulation of desire as a consequence of the pleasure that was experienced by realising previously articulated desires, and of the (always partial, provisional and iterative) articulated and externalisation and rationalisation of fears. 


\section{Conclusion}

As a strategy for research development, the writing groups have clearly worked to reposition participants as active scholarly writers within a peer-learning framework. They have served to build mutuality and to break down boundaries between specialisms and hitherto separate areas in the faculty. They have functioned to equip members with resources for making realistic decisions about their careers as researchers and for fostering collaborations with colleagues.

Further, the groups have also demonstrated, in their contrasts with each other, that there is no particular 'right' way or style needed for successful functioning. The convenors involved have each brought very different skills, experiences and interests into the groups, though we shared a common commitment to investing in our colleagues. Further groups have formed and are working with different members in quite distinct ways. We conclude that the idea of writing groups in the current university environment is robust enough, given the three principles outlined in the previous section, to accommodate considerable differences. That there will be considerable variation in local contexts is clear.

Developmental activities need to be situated within broad frames of timing and sequencing. In the case discussed here, the writing groups were funded in the manner described over their first few years and, as they became self-sustaining and achieved their goals, funding was gradually withdrawn. They now continue solely because members want them to. As individuals increase their publications, they move beyond the need for funded developmental support and are supported as productive research-writers through the deployment by the faculty of 'research earnings'.

The case we have made here about the role of writing groups contributes more generally to ideas of academic development. We have illustrated how a local initiative can work when it takes careful account of the local context, adapts to it and links to policy priorities and collective aspirations. It acknowledges personal and wider institutional aspirations, but does not subordinate development to the pursuit of these. It moves beyond predominantly individually focused models of academic development, associated with the accreditation of professional development, and mission-driven models based primarily on policy formulation, to a project of cultural change within the local workplace. While our own workplace may have atypical features, we believe that the approach we have adopted has potential for operating within the new environment of constant change. All workplaces are, of course, 'atypical'; it is only through acceptance of this and the contextualising of the practice of academic development that it can become meaningful and relate to those it is designed to benefit. By selecting an issue for which we anticipate an increased role for professional development - the ongoing need for academics to write, albeit in perhaps different ways - and articulating a number of principles drawn from our own practice, we have pointed to new possibilities in new forms of work.

\section{Acknowledgements}

We wish to thank the members of the writing groups we convened for their contribution 
to the development of our understanding of the issues discussed here. An earlier version of this paper was presented at the 1999 Annual Meeting of the Australian Association for Research in Education in Melbourne. In addition, a paper prepared by members of the first writing group has been published in the conference proceedings of the International Conference 'Winds of Change: women and the culture of universities' (Saunders et al., [1999], see references).

Correspondence: David Boud, Professor of Adult Education, Faculty of Education, University of Technology, Sydney, PO Box 123, Broadway, 2007, Australia; e-mail: David.Boud@uts.edu.au

\section{References}

BAUMAN, Z. (1996) From Pilgrim to Tourist-or a short history of identity, in: S. HALL \& P. DU GAY (Eds) Theories of Cultural Identity, pp. 18-36 (London, Sage).

BOLER, M. (1999) Feeling Power: emotions and education (London, Routledge).

BOUD, D. (1995) Meeting the challenge, in: A BREW (Ed.) Directions in Staff Development, pp. 203-213. (Buckingham, Open University Press).

BOUD, D. (1999) Situating academic development in professional work: using peer learning, International Journal for Academic Development, 4, pp. 3-10.

BOUD, D. \& MILLER, N. (1996) Synthesising traditions in learning from experience, in: D. BOUD \& N. MILLER (Eds) Working with Experience: animating learning, pp. 14-24 (London, Routledge).

BOURDIEU, P. (1986) The forms of capital, in: J.G. RICHARDSON (Ed.) Handbook of Theory and Research for the Sociology of Education, pp. 241-258 (New York, Greenwood Press).

BRODKEY, L. (1996) Writing Permitted in Designated Areas Only (Minneapolis, MN, University of Minnesota Press).

DELEUZE, G. \& GUATTARI, F. (1983) Anti-Oedipus: capitalism and schizophrenia, trans. Robert Hurley, Mark Seem \& Helen R. Lane (Minneapolis, MN, University of Minnesota Press). ThbdrRe oPD(16905’Melbourne, Melbourne University Press).

GARRICK, J. \& RHODES, C. (Eds) (2000) Research and Knowledge at Work: perspectives, case studies and innovative strategies (London, Routledge).

(1987) Writing groups in academic institutions, in: Writing Groups: history, theory and implications, pp. 9-31 (Carbondale, IL, Southern Illinois University Press).

GIBBONS, M., LIMOGES, C., NOWOTNY, H., SCHWARTZMAN, S., SCOTT, P. \& TROW, M. (1994) The New Production of Knowledge: the dynamics of science and research in contemporary societies (London, Sage). 
GRANT, B. \& KNOWLES, S. (1999) 'Doing writer'/flights of imagination: academic women making spaces for writing, Proceedings of the 'Winds of Change: women and the culture of universities', International conference, University of Technology, Sydney, July 1998, pp. 659-666.

HALL, S. (1996) Introduction: Who needs Identity? in: S. HALL \& P. DU GAY (Eds) Theories of Cultural Identity, pp. 1-17 (London, Sage).

JONES, G., LEE, A. \& POYNTON, C. (1998) Discourse analysis and policy activism: readings and re-writings of Australian university research policy, in: A. YEATMAN (Ed.) Policy Activism and the State, pp. 124-142 (Sydney, Allen \& Unwin).

KEMP, D.A. (1999) Knowledge and Innovation: a policy statement on research and research training (Canberra, Department of Education, Training and Youth Affairs).

LEE, A. (1998) Doctoral research as writing, in: J. HIGGS (Ed.) Writing Qualitative Research, pp. 124-142 (Sydney, Hampden Press).

LEE, A. \& GREEN, B. (1997) Pedagogy and disciplinarity in the 'new' university, UTS Review, 3, pp. 1-25. MANSFIELD, N. (2000) Subjectivity: theories of the self from Freud to Haraway (Sydney, Allen \& Unwin).

MCWILLIAM, E. (1995) (S)education: a risky inquiry into pleasurable teaching, Education and Society, 13, pp. 15-24.

MCWILLIAM, E. \& TAYLOR, P. (1996) Pedagogy, Technology and the Body (New York, Peter Lang).

PATTON, P. (2000) Desire, becoming and freedom, in: Deleuze and the Poetical, pp. 68-87 (London,

Routledge). $\quad$ S\$NABSDER \$., \&.LEE, A. (1999) Writing along new lines, Proceedings of the 'Winds of Change: women and the culture of universities', International conference, University of Technology, Sydney, July 1998, pp. 705-714.

SYMES, C. \& MCINTYRE, J. (Eds) (2000) Working Knowledge: the new vocationalism and higher education (Buckingham, Open University Press). 